\title{
(2) OPEN ACCESS \\ Benefits outweigh the risks: a consensus statement on the risks of physical activity for people living with long-term conditions
}

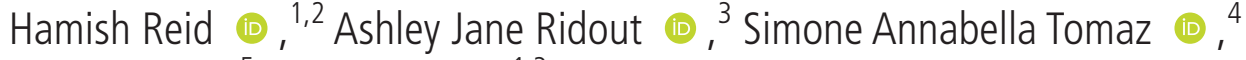 \\ Paul Kelly $10,{ }^{5}$ Natasha Jones, ${ }^{1,3}$ on behalf of the Physical Activity Risk Consensus \\ group
}

\begin{abstract}
- Additional supplemental material is published online only. To view, please visit the journal online (http://dx.doi. org/10.1136/bjsports-2021104281).
\end{abstract}

${ }^{1}$ Moving Medicine, Faculty of Sport And Exercise Medicine Edinburgh, UK

${ }^{2}$ Advanced Wellbeing Research Centre, Sheffield Hallam University, Sheffield, UK ${ }^{3}$ Sport and Exercise Medicine, Oxford University Hospitals NHS Foundation Trust Nuffield Orthopaedic Centre, Oxford, UK ${ }^{4}$ Stirling Physical Activity Research Knowledge and Learning Exchange (SPARKLE), University of Stirling, Stirling, UK ${ }^{5}$ Physical Activity for Health Research Centre, University of Edinburgh Institute for Sport Physical Education and Health Sciences, Edinburgh, UK

\section{Correspondence to}

Dr Natasha Jones, Sport and Exercise Medicine, Oxford University Hospitals NHS Foundation Trust Nuffield Orthopaedic Centre, Oxford, Oxfordshire, UK

natasha.jones@ouh.nhs.uk

Accepted 16 September 2021

Check for updates

(C) Author(s) (or their employer(s)) 2021. Re-use permitted under CC BY-NC. No commercial re-use. See rights and permissions. Published by BMJ.

To cite: Reid H, Ridout AJ, Tomaz SA, et al.

Br J Sports Med Epub ahead of print: [please include Day Month Year]. doi:10.1136/ bjsports-2021-104281

\section{ABSTRACT}

Introduction The benefits of physical activity for people living with long-term conditions (LTCS) are well established. However, the risks of physical activity are less well documented. The fear of exacerbating symptoms and causing adverse events is a persuasive barrier to physical activity in this population.

This work aimed to agree clear statements for use by healthcare professionals about medical risks of physical activity for people living with LTCs through expert consensus. These statements addressed the following questions: (1) Is increasing physical activity safe for people living with one or more LTC? (2) Are the symptoms and clinical syndromes associated with common LTCs aggravated in the short or long term by increasing physical activity levels? (3) What specific risks should healthcare professionals consider when advising symptomatic people with one or more LTCs to increase their physical activity levels?

Methods Statements were developed in a multistage process, guided by the Appraisal of Guidelines for Research and Evaluation tool. A patient and clinician involvement process, a rapid literature review and a steering group workshop informed the development of draft symptom and syndrome-based statements. We then tested and refined the draft statements and supporting evidence using a three-stage modified online Delphi study, incorporating a multidisciplinary expert panel with a broad range of clinical specialties.

Results Twenty-eight experts completed the Delphi process. All statements achieved consensus with a final agreement between $88.5 \%-96.5 \%$. Five 'impact statements' conclude that (1) for people living with LTCs, the benefits of physical activity far outweigh the risks, (2) despite the risks being very low, perceived risk is high, (3) person-centred conversations are essential for addressing perceived risk, (4) everybody has their own starting point and (5) people should stop and seek medical attention if they experience a dramatic increase in symptoms. In addition, eight symptom/ syndrome-based statements discuss specific risks for musculoskeletal pain, fatigue, shortness of breath, cardiac chest pain, palpitations, dysglycaemia, cognitive impairment and falls and frailty.

Conclusion Clear, consistent messaging on risk across healthcare will improve people living with LTCs confidence to be physically active. Addressing the fear of adverse events on an individual level will help healthcare professionals affect meaningful behavioural change in day-to-day practice. Evidence does not support routine preparticipation medical clearance for people with stable
LTCs if they build up gradually from their current level. The need for medical guidance, as opposed to clearance, should be determined by individuals with specific concerns about active symptoms. As part of a systemwide approach, consistent messaging from healthcare professionals around risk will also help reduce crosssector barriers to engagement for this population.

\section{INTRODUCTION}

The International Society for Physical Activity and Health identified the healthcare sector as one of the eight best investments to combat global population inactivity. ${ }^{12}$ Consequently, there is much interest in the UK and globally on using healthcare effectively and efficiently to promote physical activity. ${ }^{3}$ The translation of this public health objective into clinical practice is notoriously challenging. Barriers are complex and multifactorial. Healthcare professionals cite a lack of the knowledge and skills required to reassure and motivate people with longterm conditions (LTCs) who are concerned that physical activity may aggravate their symptoms or even cause sudden death. ${ }^{4-7}$

In their recently updated physical activity guidelines, the WHO highlighted increasing inactivity levels globally and updated public health recommendations. ${ }^{8}$ They explicitly recommend physical activity as beneficial for adults with LTCs, ${ }^{8}$ recognising that inactivity levels double in those groups. ${ }^{9}$ The WHO Guideline Development Group rated adverse events as critical to clinical decision-making on physical activity. It commissioned an umbrella review reporting on adverse events around physical activity for adults in general, including pregnancy and post partum. ${ }^{8}$ However, they excluded evidence reporting on clinical populations with the rationale that the data cannot be generalised to the broader population. ${ }^{10}$ They did look specifically at the benefit to some clinical subgroups (cancer, HIV, hypertension and type 2 diabetes mellitus), but data about risk is less well defined and limited to broad comparatives. The WHO concluded that for all people, doing some physical activity is better than none. Medical clearance is generally unnecessary, provided the amount and intensity of physical activity are increased gradually. ${ }^{8}$ They recommend people who develop new symptoms should seek medical advice but do not clarify what that advice should be or how it relates to risk. 
Epidemiological studies show that multimorbidity is common (62\% in the over 65 's and $81 \%$ in the over 85 's) and constitutes most routine clinical presentations. ${ }^{11}$ Projections suggest that in the UK, complex presentations of individuals with four or more LTC will double by 2032 , emphasising the importance of designing services to support the management of these people. ${ }^{12}$ The literature about physical activity in LTCs is predominantly condition-specific (see online supplemental file 1). Previous guidelines and consensus statements on risk have also focused on adverse events in defined conditions making recommendations challenging to implement in a multimorbid population.

In summary, public health bodies and clinical guidelines are clear that physical activity should be central to almost all LTC management. However, a barrier to this is particular patient concerns surrounding risk, which generally relate more to their symptoms than their conditions. As a result, it is unclear how healthcare professionals should address physical activity or share relevant information during routine healthcare interactions. This consensus statement aims to address this evidence gap, to clarify the fundamental safety considerations that will inform the conversations on physical activity between healthcare professionals and symptomatic people with LTCs. It will form a bridge between clinical practice guidelines, public health guidelines and people's lived experience to address valid concerns that increasing physical activity might be unsafe or worsen their symptoms.

\section{AIMS}

The aim of this project was to agree clear statements, through expert consensus, about the medical risks of physical activity for all adults, irrespective of age, living with one or more LTC. These statements are for healthcare professionals to support them during clinical practice.

It will address these commonly encountered questions:

- Is increasing physical activity safe for people living with one or more LTC?

- Are the symptoms and clinical syndromes associated with common LTCs aggravated in the short or long term by increasing physical activity levels?

- What specific risks should healthcare professionals consider when advising symptomatic people with one or more LTC to increase their physical activity levels?

\section{METHODS}

This is a multistage study with four discrete but related stages, each involving separate multidisciplinary working groups (see table 1). Table 2 demonstrates group roles and recruitment strategies. A complete list of contributors is in online supplemental file 2. This consensus statement has been developed according to the Appraisal of Guidelines for Research and Evaluation tool ${ }^{13}$ and will be reviewed in 5 years unless advances in light of new or emerging scientific evidence prompt an earlier update.

\section{Stage 1: preparation}

The preparatory stage aimed to understand the opinion and perspectives of healthcare professionals and people living with LTCs on the risks of physical activity and how to address them during routine healthcare visits. Full details of the preparatory stage are in online supplemental file 3.

\section{Patients and the public}

We incorporated results from two related but discrete projects to inform our understanding from the patient and public perspective.
1. Patient and public involvement project to explore service users' experiences and views on how the National Health Service could better support their needs. ${ }^{7}$

2. A national consultation with 361 members of the public led by The National Centre for Sport and Exercise Medicine at Sheffield Hallam University in collaboration with Sport England. This related piece of work helped further inform our understanding of patient preferences and successful approaches to improving physical activity support for people with LTCs. ${ }^{14}$

\section{Practitioners}

We undertook an open question survey of the practitioner group to better understand risk perception in clinical practice, including barriers and facilitators to implementing and disseminating recommendations.

\section{Stage 2: rapid evidence review}

We undertook a rapid review of the literature to establish what is known about the risks of physical activity in people with LTCs. This type of review 'aims to assess what is already known about a policy or practice issue, using systematic review methods to search and critically appraise existing research". ${ }^{15}$

The rapid review aimed to provide an overview of existing guidelines and/or recommendations that address the risks of physical activity for people with LTCs, including:

1. What has previously been done to understand the associated risks?

2. What conclusions or consensus were reached?

3. How were conclusions or consensus reached?

The methods and full search strategy are in online supplemental file 1.

\section{Stage 3: steering group meeting}

The terms of reference for the steering group were to agree on core messages, review contraindication advice, develop consensus statement format, identify clinical priorities, approve statement development plan and ratify the delphi protocol.

The steering group appraised the results from the preparation phase and evidence review before a face-to-face workshop in November 2019. The meeting focused on the results of the preparation phase and evidence review, followed by a group discussion focussing on the terms of reference above.

Following the meeting, we reviewed the evidence base and recategorised it into a symptoms/syndrome format. In addition, we extended the literature review to address areas of specific clinical concern identified by the steering group. We then drafted consensus statements reflecting the outcomes of the steering group meeting. The draft statements and updated evidence summaries were then shared with the steering group via email for free-text comments and statements modified accordingly. We developed an online survey testing the content, structure, hierarchy of information and wording of the consensus statements. We piloted the survey with six healthcare professionals not involved in the project to ensure clarity, feasibility, and comprehensibility.

\section{Stage 4: delphi study}

We used a modified online version of the Delphi process ${ }^{16-19}$ following the Conducting and REporting DElphi Studies guidelines. ${ }^{18}$ Online survey rounds used the commercial software 'SurveyMonkey'. ${ }^{20}$ Target completion time was below $30 \mathrm{~min}$. Level of agreement used a scale of 1 (strongly disagree) to 6 
Table 1 Group objectives and overview of study stages

\begin{tabular}{|c|c|c|c|c|c|}
\hline & & Study stage & & & \\
\hline & & 1. Preparation & 2. Rapid evidence review & 3. Steering group meeting & 4. Delphi \\
\hline \multirow[t]{4}{*}{$\begin{array}{l}\text { Group } \\
\text { objectives }\end{array}$} & Authorship group & $\begin{array}{l}\text { Establish a collaborative network of } \\
\text { stakeholders } \\
\text { Consider the scope and context of this } \\
\text { consensus statement } \\
\text { Understand the perspectives of } \\
\text { healthcare professionals and people } \\
\text { living with LTCs on the risks of } \\
\text { physical activity and relationship with } \\
\text { clinical conversations }\end{array}$ & $\begin{array}{l}\text { Undertake a rapid } \\
\text { review of published } \\
\text { literature to establish } \\
\text { what is known about } \\
\text { the risk of physical } \\
\text { activity in people with } \\
\text { LTCs }\end{array}$ & $\begin{array}{l}\text { Coordinate steering } \\
\text { group meeting } \\
\text { Recruit delphi panel } \\
\text { Develop questionnaire } \\
\text { Develop draft statements }\end{array}$ & $\begin{array}{l}\text { Lead the evolution } \\
\text { of clear statements, } \\
\text { through expert } \\
\text { consensus, about the } \\
\text { medical risks of physical } \\
\text { activity for all adults, } \\
\text { irrespective of age, living } \\
\text { with one or more LTCs }\end{array}$ \\
\hline & Stakeholder group & $\begin{array}{l}\text { Agree scope of the consensus project } \\
\text { Map cross-sector context } \\
\text { Build collaboration }\end{array}$ & & & $\begin{array}{l}\text { Review outputs from the } \\
\text { delphi study } \\
\text { Establish common } \\
\text { terminology and } \\
\text { approach to inform } \\
\text { subsequent cross-sector } \\
\text { work }\end{array}$ \\
\hline & Practitioner group & $\begin{array}{l}\text { Provide an overview of the perception } \\
\text { of giving advice around risk from } \\
\text { physical activity in clinical practice } \\
\text { Outline barriers and facilitators } \\
\text { to implementing physical activity } \\
\text { recommendations }\end{array}$ & & & \\
\hline & Steering group & & $\begin{array}{l}\text { Appraise rapid evidence } \\
\text { review } \\
\text { Contextualise findings } \\
\text { related to clinical } \\
\text { practice }\end{array}$ & $\begin{array}{l}\text { Recommend format of } \\
\text { statements } \\
\text { Review draft statements } \\
\text { for testing in the delphi } \\
\text { study }\end{array}$ & \\
\hline
\end{tabular}

LTCs, long-term conditions.

(strongly agree) with space for free-text comments and suggestions where appropriate.

If invited participants did not reply to the initial contact, we checked the contact details and made one further effort. For the second and third phases, participants were invited by email. Reminders were sent out for non-responders at 2 weeks, 1 week and 2 days before survey closure. We took implied consent from the willingness to complete the survey. No participants stood to gain financially or otherwise from decisions taken in the delphi study.

\section{Between phase feedback}

We prepared individualised feedback for participants following each phase, which compared their response to each question with the group average. We presented a summary of free-text responses with associated modifications to each statement. The Delphi group received the supporting evidence summaries alongside each statement in the survey, and their recommendations informed the evolution of these summaries.

We maintained communication with participants through a project administrator to avoid imposing any opinion bias from the authorship group. ${ }^{21}$

\section{Pre-defined consensus criteria}

In keeping with described methods, ${ }^{17}{ }^{21}$ satisfactory agreement for phase 1 required both:

- Average score: $>80 \%$.

- All responses >3 (ie, no participant disagreement).

We removed questions meeting these criteria for the second phase of the delphi. Questions with an average score $>80 \%$, but with one or more participants scoring 1-3, were interrogated for free-text feedback.

In phase 2 , agreement was further stratified with $>80 \%$ high agreement, satisfactory agreement range between $60 \%$ and $80 \%$. 
Consensus statement

Table 2 Group roles and recruitment

\begin{tabular}{|c|c|c|}
\hline Group & $\mathrm{n}$ & Group roles and recruitment \\
\hline Authorship group & 5 & $\begin{array}{l}\text { The authors form a collaboration between the Faculty of Sport and Exercise Medicine (FSEM) and The Physical Activity for Health Research } \\
\text { Centre, University of Edinburgh. The authorship group led all phases of this study. }\end{array}$ \\
\hline Stakeholder group & 4 & $\begin{array}{l}\text { External stakeholders from Sport England—health and inactivity, Public Health England—physical activity and healthy weight and the Royal } \\
\text { College of General Practitioners (RCGP)—physical activity clinical priority group. The stakeholder group agreed on the remit of the consensus } \\
\text { project and reviewed the completed statement. Members of this group were invited to the steering group meeting. This consensus statement } \\
\text { will inform the direction of future cross-sector work by these organisations. }\end{array}$ \\
\hline Practitioner group & 57 & $\begin{array}{l}\text { We recruited this group of healthcare professionals through stakeholder organisations, including FSEM, RCGP, Chartered Society of } \\
\text { Physiotherapy, Royal College of Nursing and Royal College of Physicians. This group participated in an online survey to help us understand } \\
\text { opinions and perspectives from a group of healthcare professionals who do not have a specific clinical interest in physical activity but have } \\
\text { the opportunity to discuss physical activity with patients routinely. }\end{array}$ \\
\hline $\begin{array}{l}\text { Patient and public } \\
\text { involvement groups }\end{array}$ & 401 & $\begin{array}{l}\text { We incorporated results from two studies exploring service users' views and experience of physical activity support around risk in healthcare } \\
\text { that closely aligned with our objectives. We combined findings from these studies to provide vital insight on how people living with LTCs feel } \\
\text { the NHS could better support their physical activity needs. }\end{array}$ \\
\hline Steering group & 13 & $\begin{array}{l}\text { We recruited multidisciplinary healthcare professionals with extensive clinical and/or academical experience in using physical activity to } \\
\text { manage LTCs through professional contacts of the authorship and stakeholder groups. This group reviewed results from the literature review } \\
\text { and preparation phases and met with the authorship group at a face-to-face meeting in November } 2019 \text { to agree on the approach and } \\
\text { direction of the study. }\end{array}$ \\
\hline Delphi group & 29 & $\begin{array}{l}\text { Recruitment for the modified Delphi study aimed to generate a heterogeneous group of professionals covering a broad range of professional } \\
\text { groups and clinical disciplines to ensure diversity in opinion and expertise. Following introductions from professional organisations and } \\
\text { clinical networks, we recruited experts by direct invitation. We used the delphi group to test and develop the structure and content of the } \\
\text { statements. For this modified delphi, requiring in-depth feedback and continuity from a range of specialist areas, we set a minimum of } 20 \\
\text { participants. }\end{array}$ \\
\hline
\end{tabular}

LTCs, long-term conditions; NHS, National Health Service.

The study protocol included a potential third round of the delphi for items not achieving satisfactory agreement. This eventuality would require participants to vote on potential solutions. This approach facilitates timely progression and mitigates risks from survey fatigue. ${ }^{22}$

\section{RESULTS}

In this section we report results by study stage followed by the consensus statements themselves.

\section{Stage 1: preparation}

Summary recommendations from the preparation phase are in table 3. Full results from the preparation phase are in online supplemental file 3 .

\section{Stage 2: rapid evidence review}

Seventy-nine relevant reports (reviews, consensus statements, position statements or guidelines) were reviewed, with findings summarised for review at the steering group workshop. See online supplemental file 1 for full rapid evidence review results.

There is considerable heterogeneity around reporting of risk and limited reporting of adverse events. In addition, variability exists within and between LTCs regarding what has been done and the specificity of recommendations or guidance.
Few studies commented on adverse events of physical activity as a primary outcome, with the majority primarily reporting the benefits of physical activity and/or exercise and only some addressing associated risks. There is heterogeneity in the nature of physical activity included in different studies (such as mode, frequency and intensity of physical activity), the specificity of adverse event reporting and inclusion/exclusion criteria for each study. In studies that did not comment on adverse events, it was not always clear whether this meant there were none or if this was not reported as an outcome. These limitations reflect the heterogeneity of LTCs, the variety of symptoms that people may experience and the broad clinical context to which this statement applies.

The evidence base on the risk of physical activity for people with LTCs is almost exclusively presented by condition rather than by symptoms. This may reflect leadership and ambition by condition-specific organisations. Nevertheless, where studies report adverse outcomes, they refer to aggravation of the symptoms of LTCs such as fatigue, breathlessness, chest pain, palpitations, dysglycaemia and so on. Therefore, this consensus statement needed to extrapolate symptom-specific data from disease-specific literature and provide clinical consensus on the generalisability of these findings across/to multimorbidity.

Table 3 Summary recommendations from preparation phase across groups

\begin{tabular}{|c|c|c|c|}
\hline Recommendation & HCP group $n=57$ & PPI group $n=40$ & NCSEM group $n=361$ \\
\hline Addressing risk is an essential facilitator for people considering increasing their physical activity levels & $\checkmark$ & $\checkmark$ & $\checkmark$ \\
\hline Statements supporting risk should be based on symptoms/clinical syndromes rather than LTCS & $\checkmark$ & $\checkmark$ & $\checkmark$ \\
\hline $\begin{array}{l}\text { Cross-sector system support is required to improve the experience of inactive people with LTCs starting to become } \\
\text { more physically active }\end{array}$ & $\checkmark$ & $\checkmark$ & $\checkmark$ \\
\hline $\begin{array}{l}\text { Continuity of advice and simple messages reduce confusion and are therefore empowering for people living with } \\
\text { LTCs }\end{array}$ & & $\checkmark$ & \\
\hline Improved resources are required to support HCP knowledge around risk & 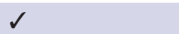 & & d \\
\hline Improved resources are required to support HCP knowledge around behavioural change & $\checkmark$ & & 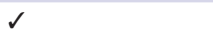 \\
\hline Removal of the need for medical clearance and implied 'liability' is required & & & 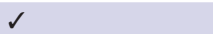 \\
\hline
\end{tabular}


Box 1 Summary recommendations from the steering group meeting

Agree core messages:

- Inactivity poses a high risk to health.

- Physical activity recommendations should consider functional level, symptoms, individual preference and social confidence.

- Address fears related to physical activity.

- The benefits outweigh the risks.

- Safety messages should include contraindications.

- Aim to safely get all patients more active or maintain healthy levels of activity.

- Understanding normal physiological responses to exercise helps individuals to identify if they have a problem.

Review contraindication advice:

- To ensure a safe approach to initiating activity, inactive people should increase activity levels gradually.

- People with unstable medical conditions require investigation.

- Fear of adverse events is a common barrier for patients and professionals.

- Safe advice should include recommendations on symptoms to look out for and where/how to report them.

Develop consensus statement format:

- Focus on risks, not benefits.

- Follow a symptom/syndrome-based rather than diagnosisbased approach.

- Focus on self-directed physical activity.

- Maintain a person-centred approach to increasing physical activity.

Identify clinical priorities:

- Symptoms to address: musculoskeletal pain, fatigue, breathlessness, cardiac suggestive chest pain, palpitations.

- Syndromes to address: cognitive impairment, dysglycaemia, falls and frailty.

Despite this, the evidence consistently reports that the benefits of physical activity outweigh any potential risks, except where explicitly contraindicated. A person-centred approach is essential, with the understanding that there is an injury risk that applies to the whole population, that tolerance of physical activity will vary with symptom severity and that supervision may be appropriate or necessary.

\section{Stage 3: steering group meeting}

Box 1 shows summary recommendations from the steering group meeting. Following advice from the steering group, we drafted statements for testing during the Delphi.

\section{Stage 4: delphi}

Qualitative feedback and subsequent statement evolution are presented in online supplemental file 4. Twenty-eight
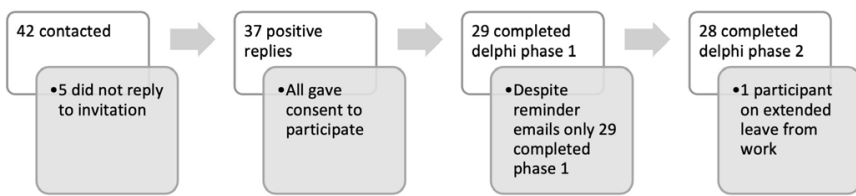

Figure 1 Recruitment of delphi participants. participants completed the Delphi study in full (see figure 1). The Delphi recorded high levels of agreement overall (see table 4). Two symptom statements that met agreement criteria in phase 1 (palpitations and falls and frailty) did not require entry into phase 2 . Despite meeting agreement criteria in phase 1 , we re-entered headline statements 1 and 2 into phase 2 for feedback following formatting changes.

Similarly, we retested the dysglycaemia statement due to substantial rewording. Following phase 2, qualitative feedback informed minor wording edits to the statements. Phase 2 achieved consensus across all domains, so we did not require a third delphi phase.

\section{Consensus statements}

We provide five 'impact statements' that every healthcare professional should know about physical activity in people with LTCs. Following this are eight symptom/syndrome-based statements supported by a summary of the relevant evidence base. Figure 2 provides an infographic summary of the results.

\section{Impact statements}

The benefits of physical activity far outweigh the risks

Physical activity is safe, even for people living with symptoms of multiple LTCs. Regular physical activity, in combination with standard medical care, has an important role in the management and prevention of many LTCs.

The risk of serious adverse events is very low, but that's not how people feel

People with LTCs are often fearful of worsening their condition or experiencing potentially undesired consequences from physical activity. In fact, when physical activity levels are increased gradually, the risk of serious adverse events is very low. Well informed, person-centred conversations with healthcare professionals can reassure people and further reduce this risk.

It is not as easy as just telling someone to move more

Successful opportunistic brief advice helps build motivation and confidence to become more physically active. This can be consolidated at further healthcare visits to support lasting behaviour change. Advice from healthcare professionals should consider the concerns of individuals and their carers, as well as individual preference, symptoms, functional capacity, psychosocial factors, social support and environmental considerations.

Everyone has their own starting point

Everyone has their own starting point, depending on their current activity level. Help people identify where they are and agree a plan to begin there and build up gradually to minimise the risk of adverse events.

Advise people to stop and seek medical review if...

they experience a dramatic increase in breathlessness, new or worsening chest pain and/or increasing glyceryl trinitrate requirement, a sudden onset of rapid palpitations or irregular heartbeat, dizziness, a reduction in exercise capacity or sudden change in vision.

\section{Symptom/syndrome statements}

Musculoskeletal pain

For people who experience musculoskeletal (MSK) pain as part of their medical condition, physical activity will not increase pain in the long term. A temporary increase in pain levels is common when starting a new physical activity, until the body adapts, and people should be counselled to expect this. There is no evidence to suggest this pain correlates with tissue damage or adverse events in the absence of new injury (acute fracture/acute soft tissue injury). 
Table 4 Consensus agreement of the delphi phases

\begin{tabular}{|c|c|c|c|c|c|c|}
\hline & & \multicolumn{3}{|l|}{ Phase 1} & \multicolumn{2}{|l|}{ Phase 2} \\
\hline & & Percentage agreement & Scores $<3$ & Consensus reached? & Percentage agreement & Consensus reached? \\
\hline \multirow[t]{4}{*}{ Headline messages } & Impact Statement 1 & $95 \%$ & 0 & Yes* & High-95\% & Yes \\
\hline & Impact Statement 2 & $94 \%$ & 0 & Yes* & High $-94 \%$ & Yes \\
\hline & Impact Statement 3 & $88 \%$ & 3 & No & High-94\% & Yes \\
\hline & Impact Statement 4 & $\mathrm{~N} / \mathrm{A}$ & & & High $-89 \%$ & Yes \\
\hline \multirow[t]{8}{*}{ Symptom statements } & Musculoskeletal pain & $92 \%$ & 1 & No & High-94\% & Yes \\
\hline & Fatigue & $91 \%$ & 2 & No & High-93\% & Yes \\
\hline & Shortness of breath & $92 \%$ & 1 & No & High-97\% & Yes \\
\hline & Cardiac chest pain & $89 \%$ & 1 & No & High $-94 \%$ & Yes \\
\hline & Palpitations & $95 \%$ & 0 & Yes & & \\
\hline & Dysglycaemia & $90 \%$ & 0 & Yes* & High $-89 \%$ & Yes \\
\hline & Cognitive impairment & $88 \%$ & 2 & No & High-95\% & Yes \\
\hline & Falls and frailty & $95 \%$ & 0 & Yes & & \\
\hline
\end{tabular}

*Despite meeting agreement in phase 1, phase 2 re-tested these statements due to substantial wording changes.

Reported evidence demonstrates that, regardless of disease severity, age, pain or level of function, physical activity (aerobic, resistance or range of motion and land or water based) is likely beneficial for reducing pain and improving function in osteoarthritis. ${ }^{23}$ Reported adverse effects are rare in studies with a physical activity component and usually relate to increased MSK pain with the physical activity intervention. ${ }^{25-29}$ Activity modification should be considered during symptomatic exacerbations, or if the activity significantly worsens pain. ${ }^{30}$ Studies of physical activity interventions in inflammatory arthropathies refer to minor MSK events, with no serious adverse events. ${ }^{31-34}$ There are limited data about adverse events in studies of people with fibromyalgia, ${ }^{35} 36$ however some people experience increased pain sensitisation in the short term, ${ }^{37-42}$ which should be addressed as part of their holistic management.

Fatigue

Regular physical activity helps reduce fatigue and improves wellbeing and sleep. A temporary increase in fatigue is commonly experienced when starting a new physical activity until the body adapts. People should be counselled to expect this and advised to

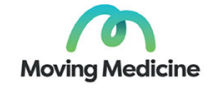

It's safer for people with long-term conditions to be physically active

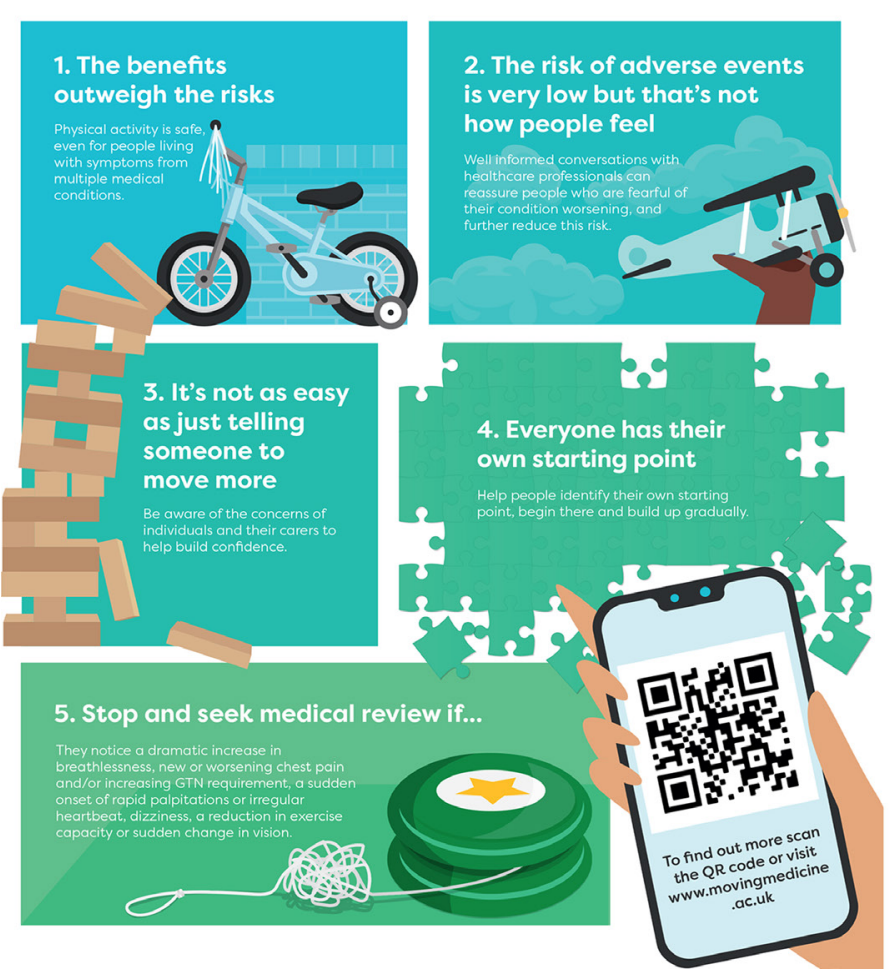

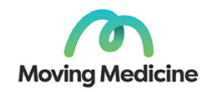

\section{Physical activity and symptoms}

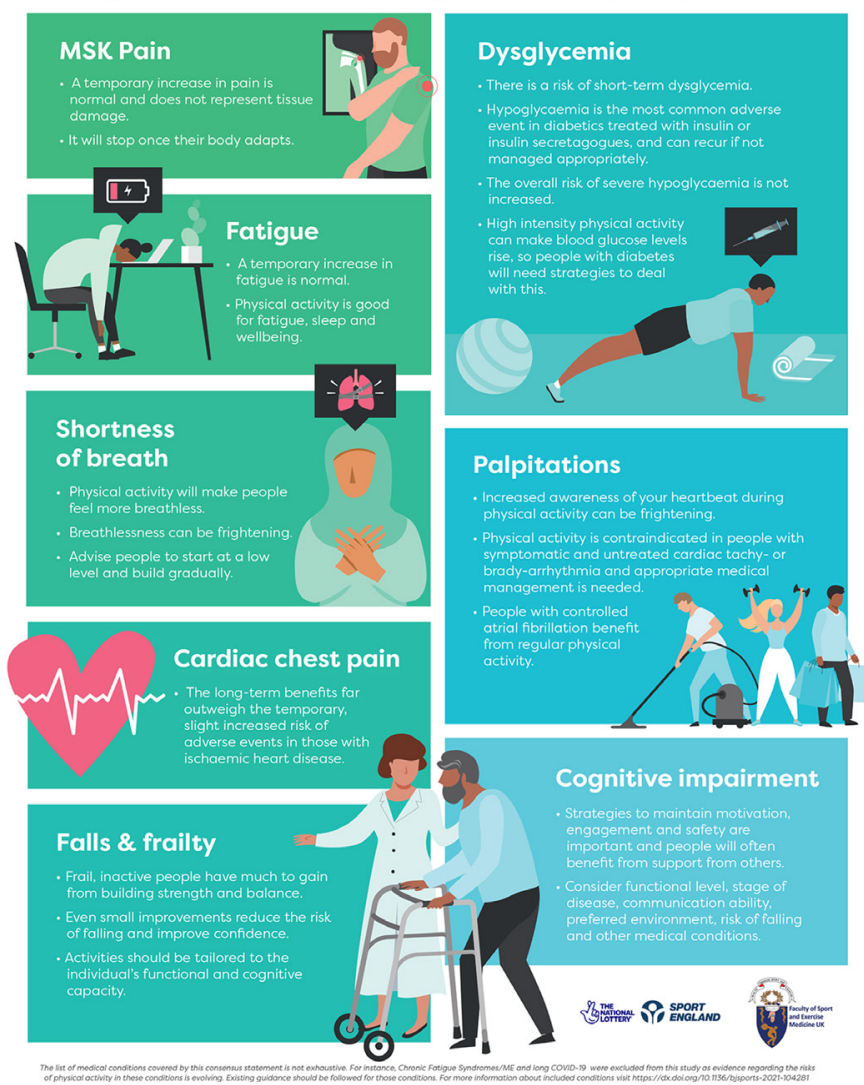

Figure 2 Infographic summary of results. 
build up activity gradually. People experiencing fatigue related to chronic fatigue syndromes may benefit from specialist advice.

Increased sedentary behaviour is associated with higher levels of fatigue. ${ }^{43}$ Adults who are more physically active report better overall well-being ${ }^{445}$ and improvements in well-being domains. ${ }^{46}$ Physical activity interventions are beneficial for fatigue in a broad range of long-term medical conditions, including rheumatoid arthritis, systemic lupus erythematosus, coronary heart disease (cardiac rehabilitation), inflammatory bowel disease, sarcoidosis, fibromyalgia and multiple sclerosis, ${ }^{47}$ and are associated with the greatest overall improvement in cancer-related fatigue (especially when compared with pharmacological treatments). ${ }^{48}$

Shortness of breath

It is normal for all people to feel more breathless when increasing their activity level. The balance of evidence suggests that the risk of adverse events in breathless people when doing physical activity is very low. People should be counselled individually to gradually increase physical activity, taking into account their severity of symptoms and fear of breathlessness.

Shortness of breath in chronic obstructive pulmonary disease (COPD) can result in progressive avoidance of physical activity ${ }^{49}$ and worsening breathlessness due to deconditioning. Reduced activity level with increasingly severe breathlessness is an important predictor of mortality. ${ }^{50}$ There are very few reported general contraindications to physical activity in individuals with COPD provided the particular activity is tolerated, comorbidities considered and recommendations individualised. ${ }^{5152}$ Increased shortness of breath, muscle cramp and soreness have been reported in physical activity interventions, especially at the beginning of the intervention. ${ }^{53}$ The weight of evidence in this area is within pulmonary rehabilitation, ${ }^{5455}$ and although not universally reported, adverse events are rare, ${ }^{54}$ including after exacerbations of COPD. ${ }^{56}$ The physiological benefits of physical activity in heart failure are well reported $^{57}$ and is associated with reduced hospital admission and reduced all-cause and cardiovascular mortality in people with heart failure after adjustment for prognostic predictors. ${ }^{58}$ Regular physical activity is associated with fewer adverse events in those with both preserved and reduced ejection fraction compared with sedentary groups. ${ }^{57}$ In stable asthma, physical activity is not associated with adverse effects or exacerbation of symptoms, and no severe adverse events have been reported. ${ }^{59-61}$ However, good asthma control and preventative strategies are important, as bronchospasm can occur.

Cardiac chest pain

The long-term benefits of increasing regular physical activity far outweigh the temporary, slight increased risk of adverse events even in those experiencing exertional chest pain as a result of ischaemic heart disease (angina). This risk increases with advancing age and exercise intensity, but overall remains very low. People should be counselled individually to gradually increase physical activity, taking into account severity of symptoms and fear of cardiac chest pain. Exercise is a good treatment option for stable angina to stimulate angiogenesis. However, increasing frequency and severity of angina should prompt a medical review with no further increase in physical activity.

In the 6 weeks after an acute cardiac event or cardiac surgery, all physical activity advice should be delivered by specialist services and outside of this document's scope. There is an increased risk of an acute cardiac event in previously sedentary individuals with known cardiovascular disease who undertake unaccustomed vigorous intensity exercise. The increased risk is present both during the activity and for 1-2hours afterwards. However, the absolute risk of a cardiovascular event during physical activity is very low. The incidence of sudden cardiac death has been reported as 1 in every 1.5 million episodes of vigorous physical activity in men $^{62}$ and every 36.5 million hours of moderate/vigorous exertion in women. ${ }^{63}$ Reports suggest a $6-17$ times increased risk of nonfatal acute myocardial infarction and sudden cardiac death during vigorous-intensity physical activity, compared with being sedentary. ${ }^{62}{ }^{64}$ This risk reduces as physical activity levels are increased and cardiovascular fitness improves. ${ }^{65}$ It is essential that levels of physical activity are increased gradually.

Until controlled by appropriate medical management absolute contraindications to physical activity include recent acute cardiac event or ECG changes suggesting significant ischaemia, unstable angina, uncontrolled dysrhythmia causing symptoms or haemodynamic compromise, severe symptomatic aortic stenosis, acute pulmonary embolus or pulmonary infarction, acute myocarditis or pericarditis, suspected or known dissecting aneurysm and acute systemic infection. ${ }^{66}$

\section{Palpitations}

An increased awareness of the heartbeat is normal during physical activity but can be frightening. Physical activity is contraindicated in people with symptomatic and untreated cardiac tachy-arrhythmia or brady-arrhythmia. Appropriate medical management should be established prior to recommending physical activity. Individuals with controlled atrial fibrillation (AF) benefit from regular physical activity, which should be started gradually.

With any perception of sudden onset or unusual change in heart rate, individuals should review how they are feeling and consider slowing down or pausing activity to let this settle. Physical activity can have a positive impact on AF both before and after its onset, although the optimal recommended physical activity prescription has not yet been defined. ${ }^{67}$ Regular physical activity is associated with a lower risk of all-cause mortality in patients with $\mathrm{AF}$, with no serious adverse events reported. ${ }^{68} 69$

\section{Dysglycaemia}

The benefits of physical activity outweigh the risks in both type 1 and type 2 diabetes. There is a risk of short-term dysglycaemia with physical activity. Hypoglycaemia is the most common adverse event associated with physical activity in people with any form of diabetes treated with insulin or insulin secretagogues. This can be recurrent if not managed appropriately. Guidelines are available to help reduce the risk of hypoglycaemia. Evidence suggests that the overall risk of severe hypoglycaemia is not increased in those who are more physically active. People with diabetes should be made aware that high intensity physical activity can cause a rise in blood glucose and offered strategies to combat this.

People with type 1 or type 2 diabetes should not start physical activity if they feel unwell or have had an episode of hypoglycaemia within the previous 24 hours. ${ }^{70}$

\section{Type 1 diabetes}

Hypoglycaemia is rare but reported as an important adverse event. ${ }^{71-73}$ People should have their blood glucose monitor with them and be vigilant with monitoring, carry diabetes identification and have a carbohydrate available. ${ }^{74}$ There may be increased risk of hypoglycaemia for 24 hours after exercise including risk of nocturnal hypoglycaemia, especially with afternoon activity. ${ }^{75}$ People should not start physical activity while ketones are abnormal, and the underlying cause should be found. ${ }^{76}$ Ketones may rise in endurance exercise, without a significant rise in serum glucose. After vigorous physical activity, hyperglycaemia may occur, so caution regarding overcorrection (potentially leading to hypoglycaemia) is required. Those with advanced neuropathy, autonomic dysfunction, end-stage renal failure or severe proliferative/non-proliferative retinopathy may require specialist advice. 
Type 2 diabetes

There are very few contraindications to physical activity in people with type 2 diabetes. ${ }^{77}$ Coexisting comorbidities should be considered. People taking insulin or insulin secretagogues have an increased risk of hypoglycaemia with physical activity. No significant adverse effects were reported in a systematic review of randomised controlled trials in people with type 2 diabetes undertaking physical activity interventions (aerobic, fitness or progressive resistance training) compared with inactive control groups. ${ }^{78}$ Minor adverse events include MSK symptoms and skin irritation. ${ }^{79}$ While those with peripheral neuropathy should be closely monitored for complications, they are no longer advised to avoid weight-bearing activities. ${ }^{80}$ Risk of skin breakdown should be considered, and well-fitted footwear that distributes load evenly is beneficial. ${ }^{79}$ No increased risk of falls, pain or neuropathic symptoms has been demonstrated in individuals with diabetic peripheral neuropathy undertaking weight-bearing activities.

\section{Cognitive impairment}

The benefits of physical activity in people with cognitive impairment far outweigh the associated risks. Strategies to maintain motivation, engagement and safety are important and people will often benefit from support from others. Strategies should consider level of function, stage of disease, communication ability (including visual and hearing impairment), preferred environment, risk of falling and other health conditions.

Reports of serious adverse effects in physical activity intervention studies are rare in people with cognitive impairment. While most report no serious adverse events, ${ }^{81} 82$ others include falls, MSK pain and chest pain after physical activity. ${ }^{83-85}$ Despite this, strength and functional training has been associated with reduced risk of falls in those with mild-moderate cognitive impairment. ${ }^{86}$ Support and supervision may be required due to cognitive impairment, balance, gait and proprioception, ${ }^{30} 87$ so appropriate equipment and safety are important, and participation may be limited by motivation, emotional control, orientation and impaired judgement.

Falls and frailty

Frail, inactive people have much to gain from increasing physical activity levels and building strength and balance, including those with osteoporosis. Even small improvements in strength and balance can reduce a frail individual's risk of falling and improve their confidence. Recommendations for physical activity should be tailored to the functional and cognitive capacity of each individual. This can be further supported by environmental aids and adaptation, such as seated exercise plans, and it may be helpful for physical activity to be accompanied.

Fear of falling is a common concern for both patients and carers, both in the community ${ }^{88}$ and in hospitals. ${ }^{89}$ Falls are a common cause of morbidity and mortality. ${ }^{90}$ Evidence from a recent systematic review demonstrates that physical activity reduced the rate of injuries from falls, including injuries requiring medical care or hospital admission. ${ }^{91}$ A large study of physical activity interventions for falls prevention in the community mainly reported non-serious adverse events (commonly MSK) and two serious adverse events. ${ }^{92}$ No serious adverse outcomes were reported in a systematic review of falls prevention classes in residential care. ${ }^{93}$ Although adverse event reporting in physical activity interventions is highly variable, a systematic review and meta-analysis of frailty management strategies ${ }^{94}$ reported that, although physical activity interventions were associated with higher rates of adverse events than other interventions, overall rates of serious adverse events (hospital admission, death, acute myocardial infarction and fracture) were lower. Nonsevere events included MSK issues, exacerbation of osteoarthritis, falls, fatigue, skin rash and vertigo.

\section{DISCUSSION}

This study aimed to develop, through expert consensus, clear statements about the medical risks of physical activity for people living with LTCs for use by healthcare professionals. Five 'impact statements' conclude that (1) for people living with LTCs, the benefits of physical activity far outweigh the risks, (2) despite the risks being very low, perceived risk is high, (3) person-centred conversations are essential for addressing perceived risk, (4) everybody has their own starting point and (5) people should stop and seek medical attention if they experience a dramatic increase in symptoms. In addition, eight symptom/syndrome-based statements discuss specific risks for MSK pain, fatigue, shortness of breath, cardiac chest pain, palpitations, dysglycaemia, cognitive impairment and falls and frailty.

Previous recommendations around the risk of prescribing physical activity in clinical practice have focused on cardiovascular risk, including the risk of sudden death. ${ }^{6595-98}$ This risk is low in both the general population and people living with LTCs, although the latter is less well described. ${ }^{62} 6399100$ Despite this, fear of adverse events and worsening symptoms remains a significant barrier for people with LTCs to building self-efficacy and initiating successful behavioural change. 56101

Preparticipation algorithms aim to help risk stratification and improve continuity between the health and physical activity and sports sectors. ${ }^{96-98} 102$ However, substantial limitations exist to the utility and effectiveness of preparticipation screening tools in the effort to balance appropriate risk identification and avoid excessive physician referrals. ${ }^{66} 103$ Since the risk of sudden death and serious adverse events to inactive people is minimal if physical activity is initiated at an appropriate level and then increased gradually, ${ }^{6595100}$ we support the WHO recommendation that routine medical screening of people with LTCs is unnecessary. ${ }^{8}$ In the event that individuals present to healthcare professionals with symptomatic concerns, successful behavioural change is unlikely unless they feel their particular concerns have been adequately addressed. ${ }^{29}$

A challenge for this study is that the risk of physical activity-related adverse events in people living with LTCs is seldom reported and poorly quantified. Much of the relevant literature is condition-specific, addressing the benefits of physical activity and heterogeneously reporting adverse events as secondary outcomes. ${ }^{100}$ The relationship between risk and clinical symptoms or syndromes is not transparent, so expert clinical consensus has been relied on to interpret this data. A limitation in the scope of this statement is that the list of medical conditions covered is not exhaustive. For instance, we do not include chronic fatigue syndrome and long COVID-19 since evidence on physical activity risk is limited and actively evolving in these areas. We cannot be sure that our symptom-specific statements translate effectively to clinical practice and subsequently to people living with these conditions. This is an important area for future research. Identifying safe and scalable strategies in healthcare to support sustainable behavioural change in the dayto-day lives of inactive people with LTCs will be a powerful asset to population approaches on physical activity. ${ }^{1}$

Operationalising effective physical activity advice in routine healthcare is a challenge in the UK and other parts of the world. ${ }^{104105}$ Despite a willingness from patients to receive advice from trusted healthcare professionals, ${ }^{106}$ support 
for patients around physical activity in preventing and managing LTCs remains inadequate. ${ }^{107}$ Although healthcare professionals generally feel physical activity is important, a disparity is observed between intentions to engage people with LTCs in conversations on physical activity and confidence in their skills and knowledge. ${ }^{108-110}$ This consensus statement will help support healthcare professional uncertainty on specific physical activity advice around risk for particular LTCs. ${ }^{111} 112$ Providing succinct information in an accessible format will support time-sensitive conversations in clinical practice. ${ }^{109111113}$ To support this aim and improve dissemination and accessibility, we will present our results in an open-access interactive format on the 'Moving Medicine' initiative website. ${ }^{104} 114115$ This website hosts a range of practical, person-centred consultation tools to support healthcare professionals having conversations on physical activity with people living with LTCs in clinical practice. This approach is in keeping with the WHO recommendation to deliver 'practice-based evidence' to narrow the gap between research and impactful public health initiatives. ${ }^{116}$

In England, this consensus statement forms part of a broader programme of work led by Sport England, Public Health England and the Royal College of General Practitioners and wider partners to improve the physical activity experience for people living with LTCs. Sport England will, in collaboration with others, explore how this consensus statement can support the removal of systemic physical activity barriers for people living with LTC's. This includes encouraging discussions with a range of partners, including the physical activity and leisure sector insurers, and supporting a review of preparticipation protocols used by health, physical activity and sport partners, including the need for medical clearance. In addition, FSEM, Sport England and the Richmond Group of Charities, alongside others, will work together to consider how we use the statements to challenge patient's perceptions about risk and physical activity including evolving them into public-facing resources that empower people's decision making and connect to wider support.

We recommend research and evaluation into the feasibility, acceptability and efficacy of implementing these statements in healthcare. Can these statements improve the knowledge and confidence of healthcare professionals to empower people with the knowledge of what symptomatic change requires medical attention? Subsequently, understanding how best to promote cross-sector integration to remove systemic barriers to physical activity participation for people living with LTCs is critical to population-wide success. We welcome further research into conditions not covered in this study and call for routine reporting of risk and adverse events in all physical activity studies of people living with LTCs.

\section{CONCLUSION}

For people living with stable LTCs, the far-reaching benefits of physical activity outweigh associated risks. We present five headline and eight symptom/syndrome specific statements to help healthcare professionals talk to people living with LTCs to address the commonly perceived fear of adverse events on an individualised basis.

We challenge recommendations that individuals with stable LTCs require medical clearance before autonomously increasing their physical activity levels. We suggest that routine preparticipation screening in this group poses an unnecessary barrier to self-directed physical activity and engagement with the physical activity, sport and leisure sectors. Our findings suggest that the need for medical guidance, as opposed to clearance, should be determined by individuals with specific concerns about active symptoms.

In isolation, better support from healthcare practitioners will not be enough to make substantial change to the physical activity levels of people with LTCs. We call for healthcare and related sectors to work together to provide continuity of advice and support through clear and consistent messaging. This consensus statement provides a starting point for developing a common language around the specific issue of risk from physical activity.

Correction notice This paper has been corrected since it was published online. Figure 2 has been replaced with an updated version and the Editor's note has also been replaced and collaborators statement updated.

Twitter Hamish Reid @drhamishreid and Paul Kelly @narrowboat_paul

Acknowledgements We are grateful for the time, energy and commitment our stakeholder group have contributed to the inception and delivery of this project together with their commitment to future dissemination and cross-sector implementation: Suzanne Gardner and Sarah Ruane on behalf of Sport England; Andrew Boyd on behalf of the Royal College of General Practitioners; Mike Brannan and Jamie Blackshaw on behalf of Public Health England and Michelle Roberts on behalf of the Richmond Group of Charities.

Collaborators We thank all Physical Activity Risk Consensus group members who gave substantial time and expertise to this project. Steering group contributors guided the development and direction of this consensus statement, providing clinical context to the evidence base. Members of this group include Charlie Foster (chair); Catherine Lester; Christopher Speers; Esther Clift; Gill Cowburn; Michelle Roberts; William Bird. Delphi group members critically appraised and informed the development of the consensus statements on risk. Members of this group include: Anna Lowe; Alastair Lumb; Amit Mistry; Andrew Murray; Anushka Soni; Brian Johnson; Cliff Kilgore; Chris Swindale; Diana Greenfield; Jordan Bowen; Julia Newton; Lucy Gossage; Muir Gray; Marie Murphy; Neil Heron; Paula Manning; Perdie Van den Berg; Robert C Andrews; Rebecca Appelboam; Rebecca Robinson; Scarlett McNally; Sally Retallick; Sarah Wheatley. The following contributed to both the steering and Delphi groups: Christopher Pugh; James H Hull; Kim Gregory; Nikant Sabharwal; Sheera Sutherland; Tracy Barnett.

Contributors NJ and HR conceptualised, planned and led the delivery of this consensus statement. NJ led stakeholder engagement. PK and SAT delivered the rapid evidence review. AJR led the translation of the rapid review into symptombased evidence statements. HR and AJR led the Delphi study. NJ and HR led the infographic development. All authors contributed to the write-up of this manuscript.

Funding Sport England has funded this work through money from the National Lottery. Of the $£ 25000$ funding made available, $£ 16660$ was spent during the development phase of this project with costs allocated to editorial and steering group travel, hire of facilities, software requirements, design agency fees and staff costs. The remaining $\mathrm{f} 8340$ will be spent on dissemination. Stakeholder group members were not involved in development of this consensus statement either through the steering or delphi processes. The authors were not prompted or paid to write this article. Collaborating authors received no financial incentive nor reward for participation in the steering or delphi groups.

Editor's note This consensus statement is endorsed by the Australasian College of Sport and Exercise Physicians, the Chartered Society of Physiotherapy, The Royal College of Nursing, the Royal College of Physicians and the Richmond Group of Charities.

Competing interests None declared.

Patient consent for publication Not applicable.

Ethics approval The original research of this study is the Delphi stage, which was conducted by the Faculty of Sport and Exercise Medicine authors. The research proposal was submitted to the UK National Health Service (NHS) Research Authority and Medical Research Council decision-making tool, which confirmed that NHS Research Ethics Committee review was not required. All participants of the Delphi and practitioner groups provided informed consent by agreeing to complete the surveys following a detailed description of what participation entailed. All Delphi participants are listed as collaborating authors.

Provenance and peer review Not commissioned; externally peer reviewed.

Supplemental material This content has been supplied by the author(s). It has not been vetted by BMJ Publishing Group Limited (BMJ) and may not have 
been peer-reviewed. Any opinions or recommendations discussed are solely those of the author(s) and are not endorsed by BMJ. BMJ disclaims all liability and responsibility arising from any reliance placed on the content. Where the content includes any translated material, BMJ does not warrant the accuracy and reliability of the translations (including but not limited to local regulations, clinical guidelines, terminology, drug names and drug dosages), and is not responsible for any error and/or omissions arising from translation and adaptation or otherwise.

Open access This is an open access article distributed in accordance with the Creative Commons Attribution Non Commercial (CC BY-NC 4.0) license, which permits others to distribute, remix, adapt, build upon this work non-commercially, and license their derivative works on different terms, provided the original work is properly cited, appropriate credit is given, any changes made indicated, and the use is non-commercial. See: http://creativecommons.org/licenses/by-nc/4.0/.

\section{ORCID iDs}

Hamish Reid http://orcid.org/0000-0003-2094-5506

Ashley Jane Ridout http://orcid.org/0000-0002-4777-3532

Simone Annabella Tomaz http://orcid.org/0000-0002-7531-3250

Paul Kelly http://orcid.org/0000-0003-1946-9848

\section{REFERENCES}

1 The International Society for Physical Activity and Health ISPAH. International Society for Physical Activity and Health's Eight Investments That Work for Physical Activity, 2020. Available: https://www.ispah.org/wp-content/uploads/2020/11/English-EightInvestments-That-Work-FINAL.pdf

2 The International Society for Physical Activity and Health. Infographic. ISPAH's Eight Investments That Work for Physical Activity: infographic, animation and call to action. Br J Sports Med 2021;55:759-60.

3 Brannan M, Bernardotto M, Clarke N, et al. Moving healthcare professionals - a whole system approach to embed physical activity in clinical practice. BMC Med Educ 2019;19:84.

4 Hunt ER, Papathomas A. Being physically active through chronic illness: life experiences of people with arthritis. Qual Res Sport Exerc Health 2020;12:242-55.

5 Franco MR, Tong A, Howard $\mathrm{K}$, et al. Older people's perspectives on participation in physical activity: a systematic review and thematic synthesis of qualitative literature. Br J Sports Med 2015;49:1268-76.

6 Yarmohammadi S, Mozafar Saadati H, Ghaffari M, et al. A systematic review of barriers and motivators to physical activity in elderly adults in Iran and worldwide. Epidemiol Health 2019;41:e2019049.

7 Jones $\mathrm{N}$, Jackson $\mathrm{K}$, Foster C. Patient and public involvement project to identify and prioritize key components of a new exercise rehabilitation service for people with multi-morbidity. 2016. OSF Prepr 2016:1-30.

8 Bull FC, Al-Ansari SS, Biddle S, et al. World Health organization 2020 guidelines on physical activity and sedentary behaviour. Br J Sports Med 2020;54:bjsports2020-102955:1451-62.

9 O'Keefe L. Active lives adult survey November 2018/19 report. Sport Engl, 2020: 1-24.

10 WHO. Who guidelines on physical activity and sedentary behaviour. Geneva, 2020.

11 Barnett K, Mercer SW, Norbury M, et al. Epidemiology of multimorbidity and implications for health care, research, and medical education: a cross-sectional study. Lancet 2012;380:37-43.

12 Kingston $A$, Robinson $L$, Booth $\mathrm{H}$, et al. Projections of multi-morbidity in the older population in England to 2035: estimates from the population ageing and care simulation (PACSim) model. Age Ageing 2018;47:374-80.

13 Brouwers MC, Kho ME, Browman GP, et al. Agree II: advancing Guideline development, reporting, and evaluation in health care. Prev Med 2010;51:j.ypmed. 2010.08.005:421-4.

14 CleverTogether. \#EasierToBeActive: Making it easier to be active with a health condition: a national conversation. Report of findings from Phase one. Sheffield, 2019. Available: https://easiertobeactive.clevertogether.com/

15 Grant MJ, Booth A. A typology of reviews: an analysis of 14 review types and associated methodologies. Health Info Libr J 2009;26:91-108.

16 Hasson F, Keeney S. Enhancing rigour in the Delphi technique research. Technol Forecast Soc Change 2011;78:1695-704.

17 Jünger S, Payne S, Brearley S, et al. Consensus building in palliative care: a Europewide Delphi study on common understandings and conceptual differences. J Pain Symptom Manage 2012;44:192-205.

18 Jünger S, Payne SA, Brine J, et al. Guidance on conducting and reporting Delphi studies (CREDES) in palliative care: recommendations based on a methodological systematic review. Palliat Med 2017;31:684-706.

19 McKenna HP. The Delphi technique: a worthwhile research approach for nursing? J Adv Nurs 1994;19:1221-5.

20 SurveyMonkey Inc, 1999. Available: www.surveymonkey.com

21 Linstone HA, Turoff M, Helmer O. The Delphi method 2002.

22 Baysari MT, Westbrook JI, Egan B, et al. Identification of strategies to reduce computerized alerts in an electronic prescribing system using a Delphi approach. Stud Health Technol Inform 2013;192:8-12.
23 Hurley M, Dickson K, Hallett R, et al. Exercise interventions and patient beliefs for people with hip, knee or hip and knee osteoarthritis: a mixed methods review. Cochrane Database Syst Rev 2018;4:CD010842

24 Mat S, Tan MP, Kamaruzzaman SB, et al. Physical therapies for improving balance and reducing falls risk in osteoarthritis of the knee: a systematic review. Age Ageing 2015:44:16-24.

25 Fransen M, McConnell S, Hernandez-Molina G, et al. Exercise for osteoarthritis of the hip. Cochrane Database Syst Rev 2014;21:CD007912.

26 Fransen M, McConnell S, Harmer AR, et al. Exercise for osteoarthritis of the knee. Cochrane Database Syst Rev 2015:1:CD004376.

27 Regnaux J-P, Lefevre-Colau M-M, Trinquart L, et al. High-Intensity versus lowintensity physical activity or exercise in people with hip or knee osteoarthritis. Cochrane Database Syst Rev 2015:CD010203.

28 Liao Chun-De, Chen Hung-Chou, Kuo Yu-Chi, et al. Effects of muscle strength training on muscle mass gain and hypertrophy in older adults with osteoarthritis: a systematic review and meta-analysis. Arthritis Care Res 2020;72:1703-18.

29 Bartels EM, Juhl CB, Christensen R, et al. Aquatic exercise for the treatment of knee and hip osteoarthritis. Cochrane Database Syst Rev 2016;3:CD005523.

30 Pedersen BK, Saltin B. Exercise as medicine - evidence for prescribing exercise as therapy in 26 different chronic diseases. Scand J Med Sci Sports : 2015;25 Suppl 3:1-72.

31 Metsios GS, Kitas GD. Physical activity, exercise and rheumatoid arthritis: effectiveness, mechanisms and implementation. Best Pract Res Clin Rheumatol 2018;32:669-82.

32 Cramp F, Hewlett S, Almeida C, et al. Non-Pharmacological interventions for fatigue in rheumatoid arthritis. Cochrane Database Syst Rev 2013:CD008322.

33 Mudano AS, Tugwell P, Wells GA, et al. Tai chi for rheumatoid arthritis. Cochrane Database Syst Rev 2019;9:CD004849.

34 Regnaux J-P, Davergne T, Palazzo C, et al. Exercise programmes for ankylosing spondylitis. Cochrane Database Syst Rev : 2019;10:CD011321.

35 Bidonde J, Busch AJ, Schachter CL, et al. Aerobic exercise training for adults with fibromyalgia. Cochrane Database Syst Rev 2017;15:CD012700.

36 Kim SY, Busch AJ, Overend TJ, et al. Flexibility exercise training for adults with fibromyalgia. Cochrane Database Syst Rev 2019;90:CD013419.

37 Ge H-Y, Nie H, Graven-Nielsen T, et al. Descending pain modulation and its interaction with peripheral sensitization following sustained isometric muscle contraction in fibromyalgia. Eur J Pain 2012;16:196-203.

38 Kosek E, Ekholm J, Hansson P. Modulation of pressure pain thresholds during and following isometric contraction in patients with fibromyalgia and in healthy controls. Pain 1996:64:415-23.

39 Lannersten L, Kosek E. Dysfunction of endogenous pain inhibition during exercise with painful muscles in patients with shoulder myalgia and fibromyalgia. Pain 2010;151:77-86

40 Meeus M, Hermans L, Ickmans K, et al. Endogenous pain modulation in response to exercise in patients with rheumatoid arthritis, patients with chronic fatigue syndrome and comorbid fibromyalgia, and healthy controls: a double-blind randomized controlled trial. Pain Pract 2015;15:98-106

41 Staud R, Robinson ME, Price DD. Isometric exercise has opposite effects on central pain mechanisms in fibromyalgia patients compared to normal controls. Pain 2005; 118:176-84.

42 Tour J, Löfgren M, Mannerkorpi K, et al. Gene-To-Gene interactions regulate endogenous pain modulation in fibromyalgia patients and healthy controlsantagonistic effects between opioid and serotonin-related genes. Pain 2017:158:1194-203.

43 Engberg I, Segerstedt J, Waller G, et al. Fatigue in the general populationassociations to age, sex, socioeconomic status, physical activity, sitting time and self-rated health: the Northern Sweden MONICA study 2014. BMC Public Health 2017; 17:654

44 Peralta M, Martins J, Gómez Chávez F, et al. Self-Rated wellbeing and physical activity associations in European older adults. Eur J Sport Sci 2018;18:1038-44

45 Bullo V, Bergamin M, Gobbo S, et al. The effects of Pilates exercise training on physical fitness and wellbeing in the elderly: a systematic review for future exercise prescription. Prev Med 2015;75:1-11.

46 Marques A, Peralta M, Martins J, et al. Associations between physical activity and self-rated wellbeing in European adults: a population-based, cross-sectional study. Prev Med 2016;91:18-23.

47 Hulme K, Safari R, Thomas S, et al. Fatigue interventions in long term, physical health conditions: a scoping review of systematic reviews. PLoS One 2018:13:e0203367.

48 Mustian KM, Alfano CM, Heckler C, et al. Comparison of pharmaceutical, psychological, and exercise treatments for cancer-related fatigue: a meta-analysis. IAMA Oncol 2017:3:961-8.

49 O'Donnell DE, Milne KM, James MD, et al. Dyspnea in COPD: new mechanistic insights and management implications. Adv Ther 2020;37:41-60.

50 Waschki B, Kirsten A, Holz O, et al. Physical activity is the strongest predictor of all-cause mortality in patients with COPD: a prospective cohort study. Chest 2011;140:331-42 
51 Vestbo J, Hurd SS, Agustí AG, et al. Global strategy for the diagnosis, management, and prevention of chronic obstructive pulmonary disease: gold executive summary. Am J Respir Crit Care Med 2013;187:347-65.

52 Santos C, Rodrigues F, Santos J, et al. Pulmonary rehabilitation in COPD: effect of 2 aerobic exercise intensities on subject-centered outcomes--A randomized controlled trial. Respir Care 2015;60:1603-9.

53 Abd El-Kader SM, Al-Jiffri OH. Exercise alleviates depression related systemic inflammation in chronic obstructive pulmonary disease patients. Afr Health $\mathrm{Sci}$ 2016;16:1078-88.

54 McCarthy B, Casey D, Devane D, et al. Pulmonary rehabilitation for chronic obstructive pulmonary disease. Cochrane Database Syst Rev 2015;3:CD003793.

55 Garvey C, Bayles MP, Hamm LF, et al. Pulmonary rehabilitation exercise prescription in chronic obstructive pulmonary disease: review of selected guidelines: an official statement from the American association of cardiovascular and pulmonary rehabilitation. J Cardiopulm Rehabil Prev 2016;36:75-83.

56 Puhan MA, Gimeno-Santos E, Cates CJ, et al. Pulmonary rehabilitation following exacerbations of chronic obstructive pulmonary disease. Cochrane Database Syst Rev 2016;12:CD005305.

57 Myers J, Brawner CA, Haykowsky MJF, et al. Prognosis: does exercise training reduce adverse events in heart failure? Heart Fail Clin 2015;11:59-72.

$58 \mathrm{O}^{\prime}$ Connor CM, Whellan DJ, Lee KL, et al. Efficacy and safety of exercise training in patients with chronic heart failure: HF-ACTION randomized controlled trial. JAMA 2009;301:1439-50.

59 Schuers M, Chapron A, Guihard H, et al. Impact of non-drug therapies on asthma control: a systematic review of the literature. Eur J Gen Pract 2019;25:65-76.

60 Carson KV, Chandratilleke MG, Picot J, et al. Physical training for asthma. Cochrane Database Syst Rev 2013:CD001116.

61 Grande AJ, Silva V, Andriolo BNG, et al. Water-based exercise for adults with asthma. Cochrane Database Syst Rev 2014:CD010456.

62 Albert CM, Mittleman MA, Chae CU, et al. Triggering of sudden death from cardiac causes by vigorous exertion. N Engl J Med 2000;343:1355-61.

63 Whang W, Manson JE, Hu FB, et al. Physical exertion, exercise, and sudden cardiac death in women. JAMA 2006;295:1399-403.

64 Mittleman MA, Maclure M, Tofler GH, et al. Triggering of acute myocardial infarction by heavy physical exertion. protection against triggering by regular exertion. determinants of myocardial infarction onset study Investigators. N Eng/ J Med 1993;329:1677-83

65 Thompson PD, Franklin BA, Balady GJ, et al. Exercise and acute cardiovascular events placing the risks into perspective: a scientific statement from the American heart association Council on nutrition, physical activity, and metabolism and the Council on clinical cardiology. Circulation 2007;115:2358-68.

66 Riebe D, Franklin BA, Thompson PD, et al. Updating ACSM's recommendations for exercise Preparticipation health screening. Med Sci Sports Exerc 2015;47:2473-9.

67 Wingerter R, Steiger N, Burrows A, et al. Impact of lifestyle modification on atrial fibrillation. Am J Cardiol 2020;125:289-97.

68 Proietti M, Boriani G, Laroche C, et al. Self-Reported physical activity and major adverse events in patients with atrial fibrillation: a report from the EURObservational research programme pilot survey on atrial fibrillation (EORP-AF) general registry. Europace 2017;19:535-43.

69 Risom SS, Zwisler A-D, Johansen PP, et al. Exercise-based cardiac rehabilitation for adults with atrial fibrillation. Cochrane Database Syst Rev 2017;2:CD011197.

70 Turner G, Quigg S, Davoren P, et al. Resources to guide exercise specialists managing adults with diabetes. Sports Med Open 2019;5:20.

71 Burr JF, Shephard RJ, Riddell MC. Physical activity in type 1 diabetes mellitus: assessing risks for physical activity clearance and prescription. Can Fam Physician 2012;58:533-5.

72 Bohn B, Herbst A, Pfeifer M, et al. Impact of physical activity on glycemic control and prevalence of cardiovascular risk factors in adults with type diabetes: a cross-sectional multicenter study of 18,028 patients. Diabetes Care 2015;38:1536-43

73 Wu N, Bredin SSD, Guan Y, et al. Cardiovascular health benefits of exercise training in persons living with type 1 diabetes: a systematic review and meta-analysis. J Clin Med 2019:8:253.

74 Riddell MC, Gallen IW, Smart CE, et al. Exercise management in type 1 diabetes: a consensus statement. Lancet Diabetes Endocrinol 2017:5:377-90.

75 Gomez AM, Gomez C, Aschner P, et al. Effects of performing morning versus afternoon exercise on glycemic control and hypoglycemia frequency in type 1 diabetes patients on sensor-augmented insulin pump therapy. J Diabetes Sci Technol 2015:9:619-24.

76 Galassetti P, Riddell MC. Exercise and type 1 diabetes (T1DM). Compr Physiol 2013;3:1309-36

77 Hoffmann TC, Maher CG, Briffa T, et al. Prescribing exercise interventions for patients with chronic conditions. CMAJ 2016;188:510-8.

78 Thomas D, Elliott EJ, Naughton GA, et al. Exercise for type 2 diabetes mellitus. Cochrane Database Syst Rev 2006;24 (6.

79 Kluding PM, Bareiss SK, Hastings M, et al. Physical training and activity in people with diabetic peripheral neuropathy: paradigm shift. Phys Ther 2016
80 Lemaster JW, Mueller MJ, Reiber GE, et al. Effect of weight-bearing activity on foot ulcer incidence in people with diabetic peripheral neuropathy: feet first randomized controlled trial. Phys Ther 2008;88:1385-98.

81 Forbes D, Forbes SC, Blake CM, et al. Exercise programs for people with dementia. Cochrane Database Syst Rev 2015:CD006489.

82 Groot C, Hooghiemstra AM, Raijmakers PGHM, et al. The effect of physical activity on cognitive function in patients with dementia: a meta-analysis of randomized control trials. Ageing Res Rev 2016;25:13-23.

83 Lamb SE, Mistry D, Alleyne S, et al. Aerobic and strength training exercise programme for cognitive impairment in people with mild to moderate dementia: the DAPA RCT. Health Technol Assess 2018;22:1-202.

84 Steinberg M, Leoutsakos J-MS, Podewils LJ, et al. Evaluation of a home-based exercise program in the treatment of Alzheimer's disease: the maximizing independence in dementia (mind) study. Int J Geriatr Psychiatry 2009;24:680-5.

85 Littbrand H, Stenvall M, Rosendahl E. Applicability and effects of physical exercise on physical and cognitive functions and activities of daily living among people with dementia: a systematic review. Am J Phys Med Rehabil 2011;90:495-518.

86 Zieschang T, Schwenk M, Becker C, et al. Falls and physical activity in persons with mild to moderate dementia participating in an intensive motor training: randomized controlled trial. Alzheimer Dis Assoc Disord 2017;31:307-14.

87 Physical activity in disease prevention and disease treatment 2010

88 Kendrick D, Kumar A, Carpenter $\mathrm{H}$, et al. Exercise for reducing fear of falling in older people living in the community. Cochrane Database Syst Rev 2014:CD009848.

89 Shuman C, Liu J, Montie M, et al. Patient perceptions and experiences with falls during hospitalization and after discharge. App/ Nurs Res 2016:31:79-85.

90 Cameron ID, Dyer SM, Panagoda CE, et al. Interventions for preventing falls in older people in care facilities and hospitals. Cochrane Database Syst Rev 2018;9:CD005465.

91 Dipietro L, Campbell WW, Buchner DM, et al. Physical activity, injurious falls, and physical function in aging: an umbrella review. Med Sci Sports Exerc 2019;51:1303-13.

92 Sherrington C, Fairhall NJ, Wallbank GK, et al. Exercise for preventing falls in older people living in the community. Cochrane Database Syst Rev 2019;1:CD012424.

93 Crocker T, Forster A, Young J, et al. Physical rehabilitation for older people in longterm care. Cochrane Database Syst Rev 2013:CD004294.

94 Negm AM, Kennedy CC, Thabane L, et al. Management of frailty: a systematic review and network meta-analysis of randomized controlled trials. J Am Med Dir Assoc 2019:20:1190-8

95 Thompson PD, Buchner D, Pina IL, et al. Exercise and physical activity in the prevention and treatment of atherosclerotic cardiovascular disease: a statement from the Council on clinical cardiology (Subcommittee on exercise, rehabilitation, and prevention) and the Council on nutrition, physical activity, and metabolism (Subcommittee on physical activity). Circulation 2003;107:3109-16.

96 Riebe D, Franklin BA, Thompson PD, et al. Updating ACSM's Recommendations for Exercise Preparticipation Health Screening. Med Sci Sport Exerc 2015:47:2473-9.

97 Bredin SSD, Gledhill N, Jamnik VK. PAR-Q+ and ePARmed-X+: new risk stratification and physical activity clearance strategy for physicians and patients alike. College of Family Physicians of Canada, 2013.

98 Hansen D, Niebauer J, Cornelissen V, et al. Exercise prescription in patients with different combinations of cardiovascular disease risk factors: a consensus statement from the expert Working group. Sports Med 2018;48:1781-97.

99 Marijon E, Tafflet M, Celermajer DS, et al. Sports-related sudden death in the genera population. Circulation 2011;124:672-81.

100 Bricca A, Harris LK, Jäger $M$, et al. Benefits and harms of exercise therapy in people with multimorbidity: a systematic review and meta-analysis of randomised controlled trials. Ageing Res Rev 2020;63:101166.

101 Teixeira PJ, Carraça EV, Markland D, et al. Exercise, physical activity, and selfdetermination theory: a systematic review. Int J Behav Nutr Phys Act 2012;9:78.

102 Thompson PD, Arena R, Riebe D, et al. ACSM's new preparticipation health screening recommendations from ACSM's guidelines for exercise testing and prescription, ninth edition. Curr Sports Med Rep 2013;12:215-7.

103 Jamnik VK, Warburton DER, Makarski J, et al. Enhancing the effectiveness of clearance for physical activity participation: background and overall process. Appl Physiol Nutr Metab 2011;36 Suppl 1:S3-13.

104 Gagliardi AR, Abdallah F, Faulkner G, et al. Factors contributing to the effectiveness of physical activity counselling in primary care: a realist systematic review. Patient Educ Couns 2015:98:412-9.

105 Brannan M, Bernardotto M, Clarke N, et al. Moving healthcare professionals - a whole system approach to embed physical activity in clinical practice. BMC Med Educ 2019;19:84

106 Keyworth C, Epton T, Goldthorpe J, et al. Perceptions of receiving behaviour change interventions from GPs during routine consultations: a qualitative study. PLoS One 2020;15:e0233399.

107 Franklin BA, Thompson PD, Al-Zaiti SS, et al. Exercise-related acute cardiovascular events and potential deleterious adaptations following long-term exercise training: placing the risks into perspective-an update: a scientific statement from the American heart association. Circulation 2020;141:E705-36. 
108 Diehl K, Mayer M, Mayer F, et al. Physical activity counseling by primary care physicians: attitudes, knowledge, implementation, and perceived success. J Phys Act Health 2015;12:216-23.

109 Huijg JM, Gebhardt WA, Verheijden MW, et al. Factors influencing primary health care professionals' physical activity promotion behaviors: a systematic review. Int J Behav Med 2015;22:32-50.

110 Hunter C, Chew-Graham CA, Langer S, et al. 'I wouldn't push that further because I don't want to lose her': a multiperspective qualitative study of behaviour change for long-term conditions in primary care. Health Expect 2015;18:1995-2010.

111 Albert FA, Crowe MJ, Malau-Aduli AEO, et al. Physical activity promotion: a systematic review of the perceptions of healthcare professionals. Int $J$ Environ Res Public Health 2020:17:4358-36.
112 Bull FC, Schipper EC, Jamrozik K, et al. How can and do Australian doctors promote physical activity? Prev Med 1997;26:866-73.

113 Hébert ET, Caughy MO, Shuval K. Primary care providers' perceptions of physical activity counselling in a clinical setting: a systematic review. Br J Sports Med 2012;46:625-31.

114 FSEM. Moving medicine, 2018

115 Douglas F, Torrance N, van Teijlingen E, et al. Primary care staff's views and experiences related to routinely advising patients about physical activity. A questionnaire survey. BMC Public Health 2006;6:138.

116 DiPietro L, Al-Ansari SS, Biddle SJH, et al. Advancing the global physical activity agenda: recommendations for future research by the 2020 who physical activity and sedentary behavior guidelines development group. Int I Behav Nutr Phys Act 2020;17:143

$\underline{\underline{c}}$ 